\title{
Structure-activity relationship of condensed tannins and synergism with trans-cinnamaldehyde against Caenorhabditis elegans
}

Article

Accepted Version

Ropiak, H. M., Desrues, O., Williams, A. R., Ramsay, A., Mueller-Harvey, I. and Thamsborg, S. M. (2016) Structureactivity relationship of condensed tannins and synergism with trans-cinnamaldehyde against Caenorhabditis elegans. Journal of Agricultural and Food Chemistry, 64 (46). pp. 87958805. ISSN 1520-5118 doi:

https://doi.org/10.1021/acs.jafc.6b03842 Available at https://centaur.reading.ac.uk/67938/

It is advisable to refer to the publisher's version if you intend to cite from the work. See Guidance on citing.

To link to this article DOI: http://dx.doi.org/10.1021/acs.jafc.6b03842

Publisher: American Chemical Society

All outputs in CentAUR are protected by Intellectual Property Rights law, including copyright law. Copyright and IPR is retained by the creators or other copyright holders. Terms and conditions for use of this material are defined in the End User Agreement. 


\section{www.reading.ac.uk/centaur}

\section{CentAUR}

Central Archive at the University of Reading

Reading's research outputs online 
Structure-activity relationship of condensed tannins and synergism with transcinnamaldehyde against Caenorhabditis elegans

Honorata M. Ropiak ${ }^{1 *}$, Olivier Desrues ${ }^{2}$, Andrew R. Williams ${ }^{2}$, Aina Ramsay ${ }^{1}$, Irene Mueller-Harvey ${ }^{1}$, Stig M. Thamsborg ${ }^{2 *}$

${ }^{1}$ Chemistry and Biochemistry Laboratory School of Agriculture, Policy and Development, University of Reading, 1 Earley Gate, Reading RG6 6AT, United Kingdom;

${ }^{2}$ Veterinary Parasitology Group, Department of Veterinary Disease Biology, University of Copenhagen, Dyrlægevej 100, 1870 Frederiksberg C, Denmark.

\section{Corresponding Author}

*E-mail: h.m.ropiak@ reading.ac.uk, smt@sund.ku.dk 


\section{ABSTRACT}

2 Parasitic gastrointestinal nematodes (GIN) of livestock are increasingly developing resistance

3 to synthetic nematocidal drugs. Moreover, the use of nematocides can induce ecotoxicity by

4 affecting free-living nematodes. Condensed tannins (CT) are a structurally diverse group of

5 bioactive plant compounds possessing anthelmintic activity against GIN. We investigated the

6 relationship between the chemical structure of contrasting, purified CT and nematocidal

7 effects using Caenorhabditis elegans. We also explored whether the nematocidal activity of

8 CT could synergize with trans-cinnamaldehyde (CIN). A non-significant correlation was

9 evident between the ability of CT fractions to inhibit C. elegans motility and the molar

10 proportion of prodelphinidin subunits in purified CT samples. Synergistic inhibition of

11 motility was achieved by combinations of CT and CIN. Galloylation of procyanidins was also

12 a key factor for synergy. To increase the nematocidal effect of CT, plant sources containing

13 CT with specific structural features could be selected and combined with compounds acting

14 in synergy.

15

16 KEYWORDS

17 condensed tannins, proanthocyanidins, procyanidins, prodelphinidins, cinnamaldehyde,

18 nematode, Caenorhabditis elegans, scanning electron microscopy 


\section{INTRODUCTION}

21 The resistance of gastrointestinal nematodes (GIN) in livestock to anthelmintic (AH) drugs is an increasing and wide spread phenomenon. ${ }^{1,2}$ The efficacy of a new AH drug can decline within a decade. ${ }^{1,3,4}$ In many livestock production systems, AH resistance has reached levels that cause compromised animal welfare and serious economic losses due to mortality and decreased productivity. ${ }^{5,6}$ Phytoparasitic nematodes are also an important economic factor in crop production ${ }^{7}$ and are typically controlled by crop rotation and/or treatment with synthetic nematocidal agents. ${ }^{8}$ Widespread use of synthetic nematocides in both crop and animal production has raised concerns in terms of adverse effects on human health, other non-target species, environmental impact and ecotoxicity by residues. ${ }^{9-11}$

There is thus a pressing need for alternative control options for GIN and phytoparasitic nematodes, one of which could be the use of natural products, ${ }^{7,8,12,13}$ some of which have already been recognized by ethno-veterinary medicine. ${ }^{13,14}$ Bioactive plant compounds such as condensed tannins $(\mathrm{CT})$ can be found in some forages ${ }^{13}$ and many medicinal plants. ${ }^{15}$ Some crops containing CT are also resistant to parasitic nematode infections, e.g. banana roots against Radopholus similis. ${ }^{16}$ Nematode-resistant crops may need less or no application of nematocides and can thereby reduce collateral damage, as even some natural product based nematocides may affect non-targeted species. ${ }^{8}$ It is well known that some CT have AH activity against various life stages of GIN that infect livestock. ${ }^{17,} 18$ Therefore, CT may potentially contribute to sustainable GIN control through their use as nutraceuticals. ${ }^{13}$

40 Research is still ongoing to pinpoint the structure-activity relationships of $\mathrm{CT}^{19-21}$ and direct

41 (pharmacological-based) or indirect (immunological-based) mechanisms of their AH action, ${ }^{22-24}$ as CT have a variety of different structures. The oligomers and polymers of CT

43 (Figure 1) are composed of monomeric subunits (flavan-3-ols), which can vary in relation to: 44 a) the B-ring, where hydroxylation gives rise to procyanidins (PC) or prodelphinidins (PD); 
b) the C-ring, i.e. cis-/trans-flavan-3-ol stereochemistry or the presence of galloyl groups; ${ }^{25}$ or c) the presence of additional A-type linkages between flavan-3-ols. ${ }^{26}$ Our group has recently conducted in vitro studies on purified CT fractions, where CT structure-AH activity has been investigated on various life stages of GIN affecting cattle [first stage larvae (L1) and adult Ostertagia ostertagi and Cooperia oncophora], ${ }^{21}$ small ruminants (L3 Haemonchus contortus $^{19,27}$ and Trichostrongylus colubriformis ${ }^{19}$ ) and pigs (L3 and/or L4 Ascaris suum ${ }^{25}$, ${ }^{28}$ ). These studies have demonstrated that CT size (mean degree of polymerization, $\mathrm{mDP}$ ), galloylation and PC/PD ratio are important factors for bioactivity. Activity also varies between nematode species, life stages (larvae ${ }^{19,21,25,27,28}$ or adults, ${ }^{21}$ with the latter generally less commonly studied) and type of assay.

The interactions of CT with other bioactive plant compounds on $\mathrm{AH}$ activity are not commonly studied, although these compounds often co-exist in the same plant materials or feed mixtures and may affect the potency of the plant material. It was recently reported that bioactive plant compounds found in the water/acetone extract of wild tamarind leaves or cocoa husks interacted with polyphenols and limited their AH effects on egg hatching of $H$.

60 contortus. ${ }^{29}$ In contrast, interactions between CT and some flavonoid monomers resulted in synergistic inhibition of L3 H. contortus exsheathment. ${ }^{27}$ However, the interactions between $\mathrm{CT}$ and other bioactive plant compounds, such as essential oil components, have not yet been investigated. Cinnamaldehyde (CIN) is the main component of the essential oil of cinnamon

64 bark, and is well-known for its anti-bacterial properties and nematocidal activity against rootknot nematodes (Meloidogyne incognita ${ }^{7}$ and $M$. javanica ${ }^{30}$ ). Recently, we also demonstrated that CIN has strong AH properties in vitro against larvae of pig GIN (A. suum, Oesophagostomum dentatum and Trichuris suis), with the mechanism-of-action qualitatively different to that of $\mathrm{CT}^{26}$ Structurally, CIN is chemically distinct from CT and as aldehydes 
have shown nematocidal activity before ${ }^{7,30}$ we tested whether CIN could represent a useful tool for assessing synergistic AH effects of CT in combination with this model aldehyde. Our overall aim in the present study was to investigate the relationship between chemical structure of CT and nematocidal effects against the free-living nematode Caenorhabditis elegans, and to assess any synergy between selected CT and CIN. C. elegans has been used in pharmacological studies of synthetic $\mathrm{AH}$ drugs, ${ }^{31}$ natural products ${ }^{32-35}$ and even highthroughput screening. ${ }^{36}$ Studies on the AH properties of CT against adult GIN are scarce ${ }^{21,37}$, ${ }^{38}$ and culturing of adult C. elegans allowed us to avoid the sacrifice of experimental ruminants or monogastric animals. We screened nematocidal activity of CT in purified fractions derived from model plant materials. ${ }^{32,33}$ These well-defined and highly contrasting CT in terms of size and structure allowed us to directly address the structure-nematocidal activity relationships of CT against an adult-stage nematode in unprecedented detail. The CT were selected to match PC against PD of a similar average size in order to reveal the CT structural characteristic that influence nematocidal activity the most. Additionally, we used a subset of CT fractions to evaluate synergistic effects with CIN. ${ }^{39}$

\section{MATERIALS AND METHODS}

\section{Reagents}

Sephadex LH-20 was obtained from GE Healthcare (Little Chalfont, UK); acetone (analytical reagent grade) from ThermoFisher Scientific (Loughborough, UK); select yeast extract (BioReagent), peptone from Glycine max (soybean), D-(+)-glucose ( $\geq 99.5 \%, \mathrm{GC})$, cholesterol (95\%), monopotassium phosphate, sodium phosphate dibasic dehydrate, sodium chloride, magnesium sulfate, potassium hydroxide, sodium hydroxide, trans-cinnamaldehyde (99\%), polyvinylpolypyrrolidone (PVPP, cross-linked) and levamisole hydrochloride ( $\geq 99 \%)$ from Sigma-Aldrich (Brøndby, Denmark); hemoglobin (from bovine blood, lyophilized, 
$94 \geq 90 \%$ ) from Fluka (Sigma-Aldrich, Brøndby, Denmark); ethanol (96\%) from

95 CHEMSOLUTE $^{\circledR}$ (Th. Geyer GmbH \& Co., Renningen, Germany); and household bleach

96 (5\% solution of sodium hypochlorite) from døgnNetto (Copenhagen, Denmark).

\section{Condensed Tannin Fractions}

98 Plant material was obtained and prepared as previously described. ${ }^{25,26,28,40}$ Briefly,

99 acetone/water extracts were fractionated on Sephadex LH-20. The resulting CT fractions F1,

100 F2, F3 (eluted by 30, 50, 80\% acetone/water, respectively ${ }^{40}$ ) were analyzed by derivatization

101 with benzyl mercaptan, RP-HPLC and LC-MS. ${ }^{15}$ The freeze-dried fractions used in this study

102 were cocoa bean F2, ${ }^{28}$ Tilia flower F2, white clover flower F2, birch leaf F2, blackcurrant

103 leaf (no. 1) F2, blackcurrant leaf (no. 2) F2 and F3, redcurrant leaf F2, yellow iris leaf F2,

104 sainfoin aerial part F2 and great water dock root F2. ${ }^{40}$

105 Maintenance and Isolation of C.elegans

106 C. elegans strain N2 (wild type) was obtained from Biotech Research \& Innovation Centre

107 (BRIC), University of Copenhagen, Denmark. Nematode eggs were collected as described

108 previously. ${ }^{41}$ Briefly, agar confluent plates were washed with sterile $\mathrm{dH}_{2} \mathrm{O}$, and the liquids

109 were collected in a sterile $15 \mathrm{~mL}$ Falcon tubes and diluted with $\mathrm{dH}_{2} \mathrm{O}$ up to $3.5 \mathrm{~mL}$. A fresh

110 mixture of $0.5 \mathrm{~mL} 5 \mathrm{M} \mathrm{NaOH}$ with $1 \mathrm{~mL}$ bleach was added, vortexed for a few sec every 2

$111 \mathrm{~min}$ for a total of $10 \mathrm{~min}$. Tubes were centrifuged for $30 \mathrm{sec}$ at $1300 \mathrm{x} \mathrm{g}$ to pellet released

112 eggs, the supernatant was removed to $0.1 \mathrm{~mL}$ and sterile $\mathrm{dH}_{2} \mathrm{O}$ was added to $5 \mathrm{~mL}$ and

113 vortexed (wash was done twice). Eggs were transferred to a sterile liquid medium. ${ }^{33}$

114 C. elegans were maintained in axenic culture medium as described previously, ${ }^{33}$ with

115 following changes: during the isolation step (see below) of the young adult and adult

116 nematode stages (henceforward referred to as adults) the larvae were kept, replenished with

117 fresh culture medium and cultured in 50-100 mL sterile Duran bottles for 6-7 days prior to

118 experiments. 
119 Adults were isolated as described previously, ${ }^{33}$ with changes e.g. to the sieves, nylon mesh

120 sizes or wash steps. In brief, sieves were composed of a modified $50 \mathrm{~mL}$ Falcon tubes and

121 nylon mesh sizes: $28 \mu \mathrm{m}$ (sieve A) and $50 \mu \mathrm{m}$ (sieve B), as nematodes in this study were

122 smaller $(\sim 35 \times 1000 \mu \mathrm{m})$. Sieves were disinfected by soaking in $70 \%$ ethanol. On average, six

123 Duran bottles were combined and passed through the sieve A, filtrate was collected and

124 larvae were cultured further (see above). The sieve A was washed with sterile $\mathrm{dH}_{2} \mathrm{O}$ to remove any remaining larvae. Retained adult worms were placed onto fresh sieve A and washed with sterile $\mathrm{dH}_{2} \mathrm{O}$. Adult worms were then transferred onto a sieve $\mathrm{B}$, which was immobilized by pegs in a $100 \mathrm{~mL}$ sterile beaker containing $50 \mathrm{~mL}$ of filter-sterilized $\mathrm{M}-9$ medium. After $15 \mathrm{~min}$, the adult nematodes migrated into the beaker and were passed through

129 a fresh sieve B. Filtrate with adult nematodes was placed in $50 \mathrm{~mL}$ Falcon tube for

130 sedimentation for $15 \mathrm{~min}$. The upper phase was removed and $1 \mathrm{~mL}$ of suspension was left

131 and used for the nematocidal assay.

\section{Adult C. elegans Motility Inhibition Assay}

133 The assay was performed as described previously. ${ }^{33}$ In brief, filter-sterilized M-9 medium ${ }^{33}$

134 was used as a measurement media and diluent for the tested CT fractions. The assay was performed in a 48 -well plate with a total volume of $250 \mu \mathrm{L} /$ well, i.e. $20 \mu \mathrm{L}$ of nematode suspension ( 50-200 nematodes per well) and corresponding tested CT fraction or medium.

137 CT fractions were used in a range of dilutions at $0,0.0625,0.125,0.25,0.5,1.0,1.5 \mathrm{mg} / \mathrm{mL}$;

138 with 3 replicates per treatment. All CT fractions were soluble under the assay conditions. The

139 negative control was M-9 medium and the positive control was $8 \mathrm{mg} / \mathrm{mL}$ of levamisole. ${ }^{32}$ The

14048 -well plates were sealed with parafilm to avoid evaporation and incubated at $24{ }^{\circ} \mathrm{C}$ for $24 \mathrm{~h}$

141 in the dark. CIN was used in a range of concentrations $0-3 \mathrm{mM}$ in three independent

142 experiments (with 3 replicates per treatment) to evaluate $\mathrm{EC}_{25}$ and $\mathrm{EC}_{50}$ (Figure S.1). The

143 concentrations related to $\mathrm{EC}_{25}(0.605 \mathrm{mM})$ and $\mathrm{EC}_{50}(0.712 \mathrm{mM})$ were further used in 
144 synergy experiments, and $\mathrm{EC}_{25}$ and at $2 \mathrm{mM}$ (where the complete motility inhibition was

145 observed) in scanning electron microscopy (SEM) imaging.

146 Plates were placed at ambient conditions for $10 \mathrm{~min}$ prior to measurement and read by using

147 an inverted microscope. Non-motile nematodes had no tail, head, or pharyngeal movements

148 during $5 \mathrm{sec}$ of observation. ${ }^{33}$ False positive results were avoided by differentiation of

149 movement caused by larvae hatched from eggs inside a dead nematode. ${ }^{33}$ The negative

150 control was between $80-100 \%$ motile and the positive control was $0 \%$ motile.

151 Condensed Tannin Depletion by PVPP Pre-treatment. PVPP pre-treatment was used to

152 check for the sample matrix effect on nematode motility, ${ }^{42}$ with changes to remove small

153 PVPP particles. In brief, $150 \mathrm{mg}$ of PVPP was mixed with $2 \mathrm{~mL}$ of measurement buffer and

154 purified by centrifugation $(3 \mathrm{~min}, 3000 \mathrm{rpm})$. The supernatant $(0.9 \mathrm{~mL})$ was removed and 0.9

$155 \mathrm{~mL}$ of fresh buffer was added, vortexed, centrifuged and these steps were repeated 3 times

156 after which PVPP was left in $1 \mathrm{~mL}$ of buffer. Corresponding CT fractions were dissolved in 1

$157 \mathrm{~mL}$ of buffer at a final concentration of $1.5 \mathrm{mg} / \mathrm{mL}$. Dissolved CT fractions, PVPP pre-

158 treated CT fractions and control (buffer only) were incubated at $4{ }^{\circ} \mathrm{C}$ overnight. ${ }^{42}$ Solutions

159 were vortexed, centrifuged and the supernatant was used in motility inhibition studies. PVPP

160 pre-treated and untreated CT fractions in triplicates were used in one independent experiment

161 at assay conditions.

162 Synergy Experiments

163 The 48-well plate was prepared at the same assay conditions as described above. The

164 treatments in the synergy experiment consisted of: a) a range of dilutions of a CT fraction in 165 triplicates (3 wells at each concentration), b) a range of dilutions of a CT fraction (3 wells at 166 each concentration) combined with a concentration of $\mathrm{CIN}$ at the $\mathrm{EC}_{25}$ value (equal to 0.605

$167 \mathrm{mM}$ ) or the $\mathrm{EC}_{50}$ value (equal to $0.712 \mathrm{mM}$ ), c) $\mathrm{CIN}$ alone at the $\mathrm{EC}_{25}$ or $\mathrm{EC}_{50}$ values (5 
wells), d) negative controls (6 wells), e) a positive control (1 well). The experiment was repeated and showed similar trends as in Figure 5-A, C (data not shown).

\section{Scanning Electron Microscopy Imaging}

171 The nematodes were incubated at assay conditions with the selected CT fractions at 1.5

$172 \mathrm{mg} / \mathrm{mL}$ with and without $\mathrm{CIN}$ at $\mathrm{EC}_{25}$, negative control, $\mathrm{CIN}$ at $\mathrm{EC}_{25}$ and $2 \mathrm{mM}$ in 24-well

173 plates. After $24 \mathrm{~h}$ of incubation the nematodes were washed twice with PBS, fixed in $2 \%$

174 glutaraldehyde in $0.05 \mathrm{M}$ phosphate buffer ${ }^{28}$ and kept at $4{ }^{\circ} \mathrm{C}$ until processed for SEM

175 imaging as described previously. ${ }^{43}$ The effect of each compound was evaluated by observing

17620 nematodes per treatment. The semi-quantitative evaluation was based on comparison of

177 the severity of damage to circumferential ridges (annuli) and furrows of the cuticle and

178 ranking it against the control nematodes.

179 Data Analysis and Statistical Analysis

180 Results from motility inhibition assay were normalized to the negative control at $100 \%$

181 motile. CT study: all measurement data were corrected to CT content (CT g/100 g of fraction)

182 and fitted to a single sigmoid function to calculate effective concentrations to inhibit

183 nematode motility at 50\% (EC50) for each CT fraction (Table 1). Standard deviations were

184 calculated from two or three independent experiments. One independent experiment was

185 composed of triplicate measurements at each CT concentration treatment. CIN study:

186 measurement from three independent experiments was averaged and fitted to a single sigmoid

187 function. $\mathrm{EC}_{25}$ and $\mathrm{EC}_{50}$ values were derived from the fit (Figure S.1). All fitting was done

188 using Pro-Data ${ }^{\mathrm{TM}}$ Software Suite (Applied Photophysics Ltd, Leatherhead, UK).

189 Shapiro-Wilk test of normality was used $(p>0.05 ; \mathrm{df}=9)$ for mDP-values, molar percentages

190 of PC and cis-flavan-3-ols, EC $50(\mathrm{mg} / \mathrm{mL})$ which excluded PC and $\mathrm{EC}_{50}$ as normally

191 distributed (natural log transformation did not change the outcome) and Spearman's rho was 
192 determined to test for statistical significance (2-tailed test, $p<0.05$ ) using the IBM $^{\circledR}$ SPSS $^{\circledR}$

193 Statistics version 21 software.

194 The predicted inhibitory effects of $\mathrm{CT}$ with $\mathrm{CIN}$ at $\mathrm{EC}_{25}$ or $\mathrm{EC}_{50}$ were calculated by Bliss

195 independence ${ }^{44}$ and compared to the observed effects as previously described. ${ }^{27,45}$ In general,

196 an observed result with a significantly greater effect than the additive effect indicates

197 synergy. A significantly lower effect indicates antagonism. The effect of synergy was

198 assessed by a two-way ANOVA with Bonferroni post-hoc testing. Graphpad Prism version 6

199 (GraphPad Software Inc., USA) was used for the statistical analysis.

200

201 RESULTS AND DISCUSSION

\section{Motility Inhibition by Condensed Tannins}

203 The CT characteristics in purified fractions represented a broad range in terms of a) size:

$204 \mathrm{mDP}$ values ranged from 5.1-16.6 and b) structure: PD contents ranged from 0-99\%, cis-

205 flavan-3-ol content ranged from 12-96\% and included one PC with 54\% galloylation (Table

206 1). Among these samples, $\mathrm{PC}$ content was not correlated with $\mathrm{mDP}\left(r_{\mathrm{s}}=-0.464 ; p=0.205\right.$;

$207 \mathrm{df}=9)$; however, it was correlated with cis-flavan-3-ol content $\left(r_{\mathrm{s}}=0.767 ; p=0.016 ; \mathrm{df}=9\right)$,

208 therefore this sample set was suitable for testing the mDP and PC effects separately. The use

209 of a range of dilutions of CT fractions allowed us to obtain motility inhibition curves for adult

210 C. elegans (Figures 1 and 2) and estimation of $\mathrm{EC}_{50}$ values (Table 1). An inhibition of

211 motility of 100\% was reached for CT of high and moderate PD content from redcurrant leaf

212 F2 at $1.4 \mathrm{mg} / \mathrm{mL}$, blackcurrant leaf (no. 2) $\mathrm{F} 2$ at $1.3 \mathrm{mg} / \mathrm{mL}$, birch leaf $\mathrm{F} 2$ at $0.64 \mathrm{mg} / \mathrm{mL}$ and

213 yellow iris leaf $\mathrm{F} 2$ at $0.8 \mathrm{mg} / \mathrm{mL}$ (Figure 2). PC from cocoa bean F2 and Tilia flower F2 were

214 clearly less potent than PD at similar CT concentrations (Figure 3-A, B). A two-fold increase

215 of the CT concentration did not induce further inhibition of motility for PC from cocoa bean

216 F2 (2.3 mg/mL, Figure 3-D) and only up to $\sim 80 \%$ inhibition of motility was reached for PC 
217 from Tilia flower F2 (to $2.8 \mathrm{mg} / \mathrm{mL}$, Figure 3-D). The galloylated PC from great water dock

218 root F2 (at $1 \mathrm{mg} / \mathrm{mL}$, Figure 3-C) were more effective in inhibiting the motility than the non-

219 galloylated PC (Figure 3-A, D); however, they were not as effective as CT with moderate or

220 high PD percentages (Figure 2). These CT results do not corroborate findings from a report

221 on the ability of flavan-3-ols at $0.5 \mathrm{mg} / \mathrm{mL}$ to inhibit the migration of $T$. colubriformis $\mathrm{L} 3$; the

222 monomeric subunits of PC, i.e. catechin and epicatechin, gave almost the same result as

223 epicatechin gallate ${ }^{46}$ (a subunit of galloylated PC from great water dock root $F 2^{40}$ ). The

224 inhibition effect of epicatechin gallate was lower than epigallocatechin and higher than

225 gallocatechin, which are the subunits of PD. ${ }^{46}$

226 The fit of the $\mathrm{EC}_{50}$ values plotted versus PD content showed a clear but non-significant

227 negative relationship $\left(R^{2}=0.98 ; r_{\mathrm{s}}=-0.617 ; p=0.077 ; \mathrm{df}=9 ;\right.$ Figure S.2 $)$. This indicated that the motility of adult $C$. elegans was affected more by fractions containing PD-rich CT compared to PC-rich CT, as seen previously with adult and L1 of C. oncophora. ${ }^{21}$

It was previously reported that CT from Japanese red pine had increasing mortality effects on C. elegans with increasing polymer size, whereas PC dimers and a trimer affected only motility. ${ }^{47}$ We did not observe any correlation between $\mathrm{EC}_{50}$ values and other $\mathrm{CT}$ characteristics such as $\mathrm{mDP}\left(r_{\mathrm{s}}=-0.317 ; p=0.406 ; \mathrm{df}=9\right)$. Furthermore, CT derived from the same plant material, blackcurrant leaf (no. 2) F2 and F3 with similar PD and cis-flavan-3-ol contents but of different mDP-values (mDP 7.8 and 16.6, respectively), resulted in a similar motility inhibition profile (Figure 2-D) and $\mathrm{EC}_{50}$ values $(0.19$ and $0.20 \mathrm{mg} / \mathrm{mL}$, respectively).

237 This indicated that nematode motility was not affected by CT size, although higher mDP values of 11.0-16.6 achieved more consistent results. The absence of a size effect agrees with the literature as CT F1 and F3 fractions from shea meal with comparable PC content (23.7 and $26.8 \%$, respectively) and galloylation (28.8 and $37.5 \%$, respectively) had similar

241 potency against the migration of $A$. suum L3 despite their average size differences (mDP 2.2 
and 7.7, respectively). ${ }^{25}$ This can also be supported by a report on L4 and young adult $C$. elegans, which had been exposed to a range of PC oligomers at $1 \mathrm{mM}$ for $72 \mathrm{~h}$. Similar survival rates were observed for tetrameric to decameric and polymeric PC. ${ }^{48}$ The $c i s$-flavan3-ols also did not contribute to the nematocidal effect $\left(r_{\mathrm{s}}=-0.183 ; p=0.637 ; \mathrm{df}=9\right)$.

Next, we investigated if nematode motility inhibition was due to CT. Selected CT fractions at $1.5 \mathrm{mg} / \mathrm{mL}$ [birch leaf F2, great water dock root F2, blackcurrant leaf (no. 1) F2, Tilia flower F2, used later in synergy studies] were pre-treated with PVPP to check for the sample matrix effect as PVPP removes CT selectively. ${ }^{42}$ It is known that PVPP can also bind to flavonol glycosides $;{ }^{49}$ however, these compounds were not detected in the purified CT fractions (data not shown). The resulting preparations did not reduce the motility of nematodes significantly (92-100\% motile), compared to untreated CT fractions (0-22\% motile) indicating that the inhibition of nematode motility was due to the $\mathrm{CT}$ in the fractions. For example, birch leaf F2 inhibited nematode motility by $100 \%$ and there was no inhibition of motility observed after pre-treatment of this CT fraction with PVPP (Figure 4).

\section{Synergistic Effect of Condensed Tannins with Cinnamaldehyde}

To evaluate the importance of structural features of CT on a potential synergistic effect with CIN we selected B-type CT with high, moderate and low PC contents: Tilia flower F2 had 99\% of CT as PC, birch leaf F2 had $41 \%$ as PC and blackcurrant leaf (no. 1) F2 had 5\% as PC. As we evaluated above, the CT size was not the main nematocidal factor in this experimental set up and, therefore, all selected B-type CT samples were chosen with moderate mDP-values (7.9, 8.3 and 11.8, respectively). Additionally, we included PC with galloylated subunits (54\%) from great water dock root F2, to evaluate effects of galloylation. We used CIN as a model for an essential oil component, as these are commonly used as feed additives in order to achieve higher intakes or digestibility of organic matter. ${ }^{39}$ The CIN 
267 selection for synergistic studies was driven by our previous findings, where cinnamon bark extract at $0.5-2 \mathrm{mg} / \mathrm{mL}$ inhibited the motility of L4 A. summ after $24 \mathrm{~h}$ exposure in vitro. ${ }^{26}$ This extract was composed mainly of PC with A- and B-type linkages and CIN (24.2 g/100 g and $7.8 \mathrm{~g} / 100 \mathrm{~g}$ of the extract, respectively). A high AH potency was attributed to the CIN.

271 We showed that pure CIN had in vitro AH activity against larvae of $A$. suum (L3, L4), $O$. dentatum (L3) and T. suis (L1)]. ${ }^{26}$ Additionally, CIN nematocidal activity affected second stage juveniles motility of M. incognita $;^{7}$ and mobility of M. javanica $;^{30}$ and doses of $>0.01$ $\mathrm{mM}$ might induce nematocidal toxicity in adult C. elegans. ${ }^{50}$

The observed effect of the CT/CIN mixture on motility was compared to the predicted additive effect. A clear synergy was observed between galloylated PC from water dock root F2 and CIN against motility of C. elegans (Figure 5). The observed effect was significantly higher than the predicted additive effect at CT concentrations of $0.16-0.96 \mathrm{mg} / \mathrm{mL}$ with CIN at $\mathrm{EC}_{25}$ (Figure 5-A), which demonstrated a significant synergy (e.g. $0.96 \mathrm{mg} / \mathrm{mL}, \mathrm{P}<0.001$ ). No synergy was observed at lower concentrations of CT. When the concentration of CIN was increased to the $\mathrm{EC}_{50}$, synergy was observed even for lower concentrations of CT $(0.08$ $\mathrm{mg} / \mathrm{mL}, \mathrm{P}<0.05)$, Figure 5-B. The synergistic effect at the highest $\mathrm{CT}$ concentration (0.96 $\mathrm{mg} / \mathrm{mL}$ ) used was close to the predicted additive range; the likely reason is that synergy was not apparent due to the high concentrations of CT and related high motility inhibition. A non-galloylated CT with high PC content from Tilia flower F2 (99\% PC) did not exhibit synergy with $\mathrm{CIN}$ at $\mathrm{EC}_{25}$ (Figure 5-C), even though the $\mathrm{CT}$ concentration range was higher

287 (up to $1.4 \mathrm{mg} / \mathrm{mL}$ ). This is consistent with previous work in which the presence of A-or Btype PC (100\% PC) did not enhance the AH effect of CIN in cinnamon bark extract. ${ }^{26}$ Therefore, it can be concluded that galloylation of PC played a crucial role in the synergy with CIN. However, it is possible that the $11 \%$ of PD in CT from great water dock roots F2 
291 (Table 1) may also have contributed to this synergistic effect, which should be investigated 292 further.

293 The other two B-type CT of low and moderate PC from blackcurrant leaf (no.1) F2 and birch

294 leaf F2 exhibited similar pattern in terms of inhibition of motility $\left(\mathrm{EC}_{50}=0.14 \mathrm{mg} / \mathrm{mL}, \mathrm{n}=3\right.$,

295 Table 1) and interaction with $\mathrm{CIN}$ at $\mathrm{EC}_{25}$. There was a synergistic effect at low

296 concentrations of CT from blackcurrant leaf (no. 1) F2 $(0.19 \mathrm{mg} / \mathrm{mL}, \mathrm{P}<0.05)$ and birch leaf

297 F2 (0.16 mg/mL, P<0.001) with CIN at EC 25 (Figure S.3).

298 There was no antagonistic effect of any of the CT tested with CIN at $\mathrm{EC}_{25}$ or $\mathrm{EC}_{50}$. Overall,

299 the most promising effect in synergy experiments was seen with purified CT from great water

300 dock root F2 (Figure 5-A).

301 AH activity of CIN in vivo could not be demonstrated against the intestinal parasite $A$. suum

302 in pigs, ${ }^{26}$ which could be due to degradation or adsorption to matrix components as shown in

303 in vitro simulations of gut fermentation. ${ }^{51}$ However, CIN could still prove useful against

304 other parasites if formulated to increase its stability and thereby reducing its disappearance

305 from the digestive tract. ${ }^{51}$ At high dose levels (above $1.6 \mathrm{~g} /$ day) CIN compromises the food

306 intake or ruminal digestion ${ }^{39}$ and this will need to be taken into account when developing

307 strategies for CIN-CT applications.

308 CT bioavailability was higher in the abomasum of ruminants than in the intestine and was

309 linked to an AH effect against O. ostertagi residing only there (in the abomasum). ${ }^{52}$ Pepsin-

310 resistant microencapsulation of $\mathrm{CT}^{53}$ could potentially be employed to increase the

311 availability of CT in the intestine. Furthermore, synergistic effects of CT and CIN could

312 perhaps be used to lower the doses of both CT and CIN while maintaining an AH effect.

314 Changes to Cuticle and Sensilla of Lip Region Observed by Scanning Electron

315 Microscopy 
316 SEM investigation showed that all treatments with CT fractions $(1.5 \mathrm{mg} / \mathrm{mL})$ induced

317 structural changes to the cuticle and sensilla of the lip region. For example, the surface of the

318 cuticle became shriveled with moderately uniform ridge formations compared to the smooth

319 cuticle of the negative control (Figures 6 and 7-C). As the damage to the sensilla of the lip

320 region varied greatly between each CT treatment, we decided to use circumferential ridges

321 (annuli) and furrows of the cuticle as a comparative factor to evaluate the visible changes.

322 The severity of the damage to the cuticle was ranked in the following order: Tilia flower F2

323 (1.38 CT mg/mL, Figure 6-C) < blackcurrant leaf (no. 1) F2 $(1.16 \mathrm{CT} \mathrm{mg} / \mathrm{mL}$, Figure 6-G) <

324 birch leaf F2 (0.95 CT mg/mL, Figure 6-E) < great water dock root F2 $(0.96 \mathrm{CT} \mathrm{mg} / \mathrm{mL}$,

325 Figure 7-C). Although Tilia flower F2 had the highest CT concentration it was the least

326 effective, which agrees with the motility studies, where PC-rich CT were also least effective

327 (Table 1). However, the birch leaf F2 with a moderate PD (59\%) level had the most potent

328 effect on the cuticle among these B-type samples (Figure 6-E). The severe changes to the

329 cuticle are in line with a previous report, where lesions were present on the cuticle of female

330 adult $H$. contortus after $24 \mathrm{~h}$ in vitro exposure to $1.2 \mathrm{mg} / \mathrm{mL}$ of sainfoin leaf extracts, ${ }^{54}$ which

331 are known to be PD-rich. ${ }^{55}$ Surprisingly, the highest level of disruption to cuticle integrity

332 was seen with galloylated PC (from great water dock root F2, Figure 7-C), despite the fact

333 that this sample was among the least effective in the motility study even at the highest

334 concentration (Figure 3-C), which was the same concentration used in SEM study (0.96 CT

$335 \mathrm{mg} / \mathrm{mL}$ ). It was shown previously that galloylation of flavan-3-ols enhanced AH effects; for

336 example, epicatechin gallate was more effective at inhibiting the exsheathment of $H$.

337 contortus and T. colubriformis L3 than epicatechin, ${ }^{56}$ and gallocatechin gallate or

338 epigallocatechin gallate were slightly more effective in reducing the feeding of an $O$.

339 ostertagi/C. oncophora L1 mixture than gallocatechin or epigallocatechin. ${ }^{21}$ Galloylated PD 
340 from shea meal F2 were also the most potent CT at inhibiting the exsheathment of $T$.

colubriformis L3 compared to other non-galloylated CT. ${ }^{19}$

342 In the present study we observed that CT with an increasing molar percentage of PD provided

343 greater inhibition of the motility of adult C. elegans, which is in line with a previous report

344 on L1 and adult C. oncophora motility. However, mDP affected feeding inhibition of L1 of

345 O. ostertagi and C. oncophora. ${ }^{21} \mathrm{CT}$ have a high affinity to proline-rich proteins ${ }^{40}$ and the

346 nematode cuticle is mostly composed of collagen-like, proline-rich proteins and structural

347 proteins such as cuticlins. ${ }^{57,58}$ The buccal cavity cuticle is lined with for example, prostom,

348 mesostom or arcade cuticles and has a different protein composition than the body cuticle,

349 which also covers the lip region. ${ }^{59,60}$ Given that the protein composition of the cuticle differs

350 between the developmental stages of nematodes, ${ }^{60}$ it is conceivable that the importance of

351 specific CT features varies between life cycle stages as the CT-protein affinities may be

352 altered. The epicuticle, i.e. the outer layer of the cuticle, contains cuticlins with a minimal

353 consensus peptide motif rich in proline in C. elegans or A. suum. ${ }^{61}$ In addition, the epicuticle

354 is lipid-rich with negatively charged glycoprotein-rich surface coat ${ }^{57}$ and the composition of

355 lipid-rich layer varies among nematode species. ${ }^{62} \mathrm{CT}$ can also interact with lipid bilayers ${ }^{63}$ or

356 lipid rafts mainly by binding to cholesterol, ${ }^{64}$ which can be found in cuticle of some

357 nematodes. ${ }^{62}$ Therefore, the primary interactions with CT are likely to occur with cuticlines

358 and by CT insertion into the (glycosylated) lipid layer. ${ }^{63}$ Secondary interactions with the

359 proline-rich layers of collagen would further disturb the hypodermal cells as already observed

360 in A. suum after CT treatment. ${ }^{28}$

361 CIN induced a less pronounced change to the cuticle than CT and there was a dose dependent

362 effect as seen after treatment with $\mathrm{CIN}$ at the $\mathrm{EC}_{25}$ or $2 \mathrm{mM}$ (Figures 7-E, G); however, there

363 were no noticeable changes to the mouth region (Figures 7-F, H). Our group reported

364 previously ultrastructural changes to the cuticle of $A$. suum L4 after exposure to CIN by 
transmission electron microscopy and the effect on furrows ${ }^{26}$ was more subtle compared to changes after exposure to CT from hazelnut pericarp. ${ }^{28}$ In the present study we used 3 and 15 times higher CIN concentrations and doubled the exposure time before SEM analysis, which still resulted in less pronounced changes to the cuticle (Figure 7-E, G) compared to nematodes treated with CT (Figure 7-C and S.3).

After combining great water dock root $\mathrm{F} 2(0.96 \mathrm{CT} \mathrm{mg} / \mathrm{mL})$ and $\mathrm{CIN}$ at $\mathrm{EC}_{25}$ there was a slight alteration to the lip region (Figure 7-J), which was not as pronounced as after treatment with CT on its own (Figure 7-D). The cuticle shriveled (Figure 7-I) in the same way as observed after CT treatment (Figure 7-C) and additional ruptures between circumferential ridges were visible (Figure 7-K). Thus, these results demonstrated that the nematocidal mode of action of CT and CIN occurred via distinct mechanisms, and treatment of nematodes with both CT and CIN causes a combination of the ultrastructural damage observed with each treatment individually. This apparent difference in mechanistic activity between CT and CIN may partly explain the possible synergistic anthelmintic effects of these molecules.

In conclusion, we demonstrated that CT containing a higher proportion of PD had the most pronounced effect on the motility of adult nematodes which may provide practical information for plant breeding programs that seek to reduce the use of nematocides. We showed that nematocidal synergy can occur at low concentrations of both galloylated PC and CIN. Based on this, it may be possible to develop better nutraceuticals, which offer a balance between $\mathrm{AH}$ and nutritional effects. This could be especially relevant for bioactive plant components with a moderate range of $\mathrm{AH}$ activities (e.g. 50-70\%), as higher $\mathrm{CT}$ or CIN concentrations can lead for example, to lower food intake. ${ }^{39,65}$ Alternatively, bioactive plant compounds could be used as feed supplements targeting one particular life cycle stage of one particular species, which could reduce general AH resistance of other species. It would be 
worthwhile to investigate further the mode of nematocidal action or associated cellular pathways of CT and CIN by employing C. elegans drug resistant strains ${ }^{34}$ or mutants. $^{36}$ Screening of CT in the presence of other plant compounds could help to identify, which combinations can act synergistically towards nematocidal effects. The use of $C$. elegans can

394 further reduce the number of experimental ruminants or monogastric animals that would need 395 to be sacrificed for drug development, e.g. for in vivo AH studies against adult GIN. ${ }^{38,66}$

396 Also, donor animals used to obtain parasitic specific nematode eggs for any initial in vitro 397 studies would not need to be maintained. This approach promotes the 'three Rs' concept 398 (replacement, refinement and reduction of animals in research) ${ }^{67}$ and should result in 399 decreased time and costs of future developments in the field of parasite control.

400

401

\section{ABBREVIATIONS USED}

402

$\mathrm{AH}$ - anthelmintic; ANOVA - analysis of variance; CIN - cinnamaldehyde; $\mathrm{CT}$ - condensed tannins; $\mathrm{EC}_{25}$ and $\mathrm{EC}_{50}-$ effective concentration to inhibit nematode motility at 25 and $50 \%$; GIN - gastrointestinal nematodes; L1, L3 and L4 - first stage larvae, third stage larvae and fourth stage larvae; $\mathrm{mDP}$ - mean degree of polymerization; $\mathrm{PC}$ - procyanidins; $\mathrm{PD}$ prodelphinidins; PVPP - polyvinylpolypyrrolidone; SEM - scanning electron microscopy.

\section{AUTHOR CONTRIBUTIONS}

HMR, OD, ARW, IMH and SMT conceived the study. HMR and OD designed the study.

410 HMR and ARW designed the synergy study. HMR prepared and analyzed fractions, carried

411 out the study and analyzed the data. ARW contributed to statistical analysis and performed

412 electron microscopy imaging. AR prepared and analyzed cocoa bean F2. HMR wrote the

413 manuscript with inputs from ARW, IMH and SMT. All authors critically read and approved

414 the final manuscript. 
ACKNOWLEDGMENTS

417 We thank Teresa D. Ropiak, Marianne Oraviita, Christos Fryganas and Peter Davy for help in 418 obtaining plant material; Teresa Rojo Romanos for obtaining C. elegans; researchers at the 419 Core Facility for Integrated Microscopy, University of Copenhagen; Lise-Lotte Christiansen 420 and Helena Mejer for technical help; Peter Nejsum, Peter Lachmann and Sundar Thapa for 421 useful discussions; Chaweewan Klongsiriwet, Christopher Drake and Parwin H Majid for 422 general help.

423

\section{Supporting Information description}

425 The Supporting Information is available free of charge on the ACS Publications website at 426 DOI:

427 Estimation of $\mathrm{EC}_{25}$ and $\mathrm{EC}_{50}$ values for cinnamaldehyde (Figure S.1); The relationship 428 between the molar percentage of prodelphinidins (PD) of condensed tannins and $\mathrm{EC}_{25}$ 429 (effective concentration at 25\% reduction of C. elegans motility) (Figure S.2); Synergistic 430 effects of CT with high or moderate molar percentages of PD on C. elegans motility in the 431 presence of CIN (Figure S.3).

432

\section{References}

434 (1) Fleming, S. A.; Craig, T.; Kaplan, R. M.; Miller, J. E.; Navarre, C.; Rings, M., 435 Anthelmintic resistance of gastrointestinal parasites in small ruminants. J. Vet. Intern. Med. 436 2006, 20, 435-444.

437 (2) Sutherland, I. A.; Leathwick, D. M., Anthelmintic resistance in nematode parasites of 438 cattle: a global issue? Trends Parasitol. 2011, 27, 176-181. 
439 (3) Van den Brom, R.; Moll, L.; Kappert, C.; Vellema, P., Haemonchus contortus resistance to 440 monepantel in sheep. Vet. Parasitol. 2015, 209, 278-280.

441 (4) Waller, P. J., From discovery to development: Current industry perspectives for the 442 development of novel methods of helminth control in livestock. Vet.Parasitol. 2006, 139, 144314.

444 (5) Fitzpatrick, J. L., Global food security: The impact of veterinary parasites and 445 parasitologists. Vet. Parasitol. 2013, 195, 233-248.

446 (6) Charlier, J.; van der Voort, M.; Kenyon, F.; Skuce, P.; Vercruysse, J., Chasing helminths 447 and their economic impact on farmed ruminants. Trends Parasitol. 2014, 30, 361-367.

448 (7) Caboni, P.; Aissani, N.; Cabras, T.; Falqui, A.; Marotta, R.; Liori, B.; Ntalli, N.; Sarais, G.; 449 Sasanelli, N.; Tocco, G., Potent nematicidal activity of phthalaldehyde, salicylaldehyde, and 450 cinnamic aldehyde against Meloidogyne incognita. J. Agric. Food Chem. 2013, 61, 17944511803

452 (8) Ntalli, N. G.; Caboni, P., Botanical nematicides: a review. J. Agric. Food Chem. 2012, 60, 453 9929-9940.

454 (9) Sánchez-Moreno, S.; Alonso-Prados, E.; Alonso-Prados, J. L.; García-Baudín, J. M., 455 Multivariate analysis of toxicological and environmental properties of soil nematicides. Pest 456 Manag. Sci. 2009, 65, 82-92.

457 (10) Floate, K. D.; Wardhaugh, K. G.; Boxall, A. B.; Sherratt, T. N., Fecal residues of 458 veterinary parasiticides: nontarget effects in the pasture environment. Annu. Rev. Entomol. 459 2005, 50, 153-179.

460 (11) Macedo, F.; Marsico, E. T.; Conte-Júnior, C. A.; Furtado, L. d. A.; Brasil, T. F.; Pereira 461 Netto, A. D., Short communication: Macrocyclic lactone residues in butter from Brazilian 462 markets. J. Dairy Sci. 2015, 98, 3695-3700. 
463 (12) Akhtar, M.; Mahmood, I., Potentiality of phytochemicals in nematode control: A review. 464 Bioresource Technol. 1994, 48, 189-201.

465 (13) Hoste, H.; Torres-Acosta, J. F. J.; Sandoval-Castro, C. A.; Mueller-Harvey, I.; Sotiraki, 466 S.; Louvandini, H.; Thamsborg, S. M.; Terrill, T. H., Tannin containing legumes as a model 467 for nutraceuticals against digestive parasites in livestock. Vet. Parasitol. 2015, 212, 5-17. 468 (14) Githiori, J. B.; Hoglund, J.; Waller, P. J., Ethnoveterinary plant preparations as livestock 469 dewormers: practices, popular beliefs, pitfalls and prospects for the future. Anim. Health Res. 470 Rev. 2005, 6, 91-103.

(15) Ropiak, H. M.; Ramsay, A.; Mueller-Harvey, I., Condensed tannins in extracts from 472 European medicinal plants and herbal products. J. Pharm. Biomed. Anal. 2016, 121, 225-231. 473 (16) Collingborn, F. M. B.; Gowen, S. R.; Mueller-Harvey, I., Investigations into the biochemical basis for nematode resistance in roots of three Musa cultivars in response to Radopholus similis infection. J. Agric. Food Chem. 2000, 48, 5297-5301.

(17) Hoste, H.; Jackson, F.; Athanasiadou, S.; Thamsborg, S. M.; Hoskin, S. O., The effects of tannin-rich plants on parasitic nematodes in ruminants. Trends Parasitol. 2006, 22, 253 478261.

479

(18) Novobilský, A.; Mueller-Harvey, I.; Thamsborg, S. M., Condensed tannins act against 480 cattle nematodes. Vet. Parasitol. 2011, 182, 213-220.

(19) Quijada, J.; Fryganas, C.; Ropiak, H. M.; Ramsay, A.; Mueller-Harvey, I.; Hoste, H., 482 Anthelmintic activities against Haemonchus contortus or Trichostrongylus colubriformis are 483 influenced by different structural features of condensed tannins. J. Agric. Food Chem. 2015, 484 63, 6346-6354.

485 (20) Novobilský, A.; Stringano, E.; Hayot Carbonero, C.; Smith, L. M. J.; Enemark, H. L.; Mueller-Harvey, I.; Thamsborg, S. M., In vitro effects of extracts and purified tannins of 
sainfoin (Onobrychis viciifolia) against two cattle nematodes. Vet. Parasitol.2013, 196, 532-

488

489

490

491

492

493

494

495

496

497

498

499

500

501

502

503

504

505

506

507

508

509

510

511 537.

(21) Desrues, O.; Fryganas, C.; Ropiak, H. M.; Mueller-Harvey, I.; Enemark, H. L.;

Thamsborg, S. M., The relation between chemical structure and in vitro anthelmintic activity of flavanols and purified condensed tannins against bovine nematodes. Parasitology 2016, http://dx.doi.org/10.1017/S0031182015001912

(22) Tibe, O.; Pernthaner, A.; Sutherland, I.; Lesperance, L.; Harding, D. R. K., Condensed tannins from Botswanan forage plants are effective priming agents of $\gamma \delta \mathrm{T}$ cells in ruminants. Vet. Immunol. Immunop. 2012, 146, 237-244.

(23) Brunet, S.; Fourquaux, I.; Hoste, H., Ultrastructural changes in the third-stage, infective larvae of ruminant nematodes treated with sainfoin (Onobrychis viciifolia) extract. Parasitol. Int. 2011, 60, 419-424.

(24) Williams, A. R.; Fryganas, C.; Reichwald, K.; Skov, S.; Mueller-Harvey, I.; Thamsborg, S. M., Polymerization-dependent activation of porcine $\gamma \delta$ T-cells by proanthocyanidins. Res. Vet. Sci. 2016, 105, 209-215.

(25) Ramsay, A.; Williams, A. R.; Thamsborg, S. M.; Mueller-Harvey, I., Galloylated proanthocyanidins from shea (Vitellaria paradoxa) meal have potent anthelmintic activity against Ascaris suum. Phytochemistry 2016, 122, 146-153.

(26) Williams, A. R.; Ramsay, A.; Hansen, T. V. A.; Ropiak, H. M.; Mejer, H.; Nejsum, P.; Mueller-Harvey, I.; Thamsborg, S. M., Anthelmintic activity of trans-cinnamaldehyde and Aand B-type proanthocyanidins derived from cinnamon (Cinnamomum verum). Sci. Rep. 2015, $5,14791$.

(27) Klongsiriwet, C.; Quijada, J.; Williams, A. R.; Mueller-Harvey, I.; Williamson, E. M.; Hoste, H., Synergistic inhibition of Haemonchus contortus exsheathment by flavonoid monomer and condensed tannins. Int. J. Parasitol. Drugs and Drug Resist. 2015, 5, 127-134. 
512 (28) Williams, A. R.; Fryganas, C.; Ramsay, A.; Mueller-Harvey, I.; Thamsborg, S. M., Direct

513 anthelmintic effects of condensed tannins from diverse plant sources against Ascaris suum.

514 PLOS ONE 2014, 9, e97053. doi:10.1371/journal.pone.0097053.

515 (29) Vargas-Magaña, J. J.; Torres-Acosta, J. F. J.; Aguilar-Caballero, A. J.; Sandoval-Castro,

516 C. A.; Hoste, H.; Chan-Pérez, J. I., Anthelmintic activity of acetone-water extracts against

517 Haemonchus contortus eggs: Interactions between tannins and other plant secondary

518 compounds. Vet. Parasitol. 2014, 206, 322-327.

519 (30) Oka, Y., Nematicidal activity of essential oil components against the root-knot nematode 520 Meloidogyne javanica. Nematology 2001, 3, 159-164.

521 (31) Geary, T. G.; Thompson, D. P., Caenorhabditis elegans: how good a model for 522 veterinary parasites? Vet. Parasitol. 2001, 101, 371-386.

523 32. Katiki, L. M.; Ferreira, J. F. S.; Gonzalez, J. M.; Zajac, A. M.; Lindsay, D. S.; Chagas, 524 A. C. S.; Amarante, A. F. T., Anthelmintic effect of plant extracts containing condensed and 525 hydrolyzable tannins on Caenorhabditis elegans, and their antioxidant capacity. Vet.

526 Parasitol. 2013, 192, 218-227.

527 (33) Katiki, L. M.; Ferreira, J. F.; Zajac, A. M.; Masler, C.; Lindsay, D. S.; Chagas, A. C.; 528 Amarante, A. F., Caenorhabditis elegans as a model to screen plant extracts and compounds 529 as natural anthelmintics for veterinary use. Vet. Parasitol. 2011, 182, 264-268.

530 (34) Waterman, C.; Smith, R. A.; Pontiggia, L.; DerMarderosian, A., Anthelmintic screening 531 of Sub-Saharan African plants used in traditional medicine. J. Ethnopharmacol. 2010, 127, $532 \quad 755-759$.

533 (35) Kumarasingha, R.; Palombo, E. A.; Bhave, M.; Yeo, T. C.; Lim, D. S. L.; Tu, C. L.;

534 Shaw, J. M.; Boag, P. R., Enhancing a search for traditional medicinal plants with 535 anthelmintic action by using wild type and stress reporter Caenorhabditis elegans strains as 536 screening tools. Int. J. Parasitol. 2014, 44, 291-298. 
537 (36) Burns, A. R.; Luciani, G. M.; Musso, G.; Bagg, R.; Yeo, M.; Zhang, Y.; Rajendran, L.;

538 Glavin, J.; Hunter, R.; Redman, E.; Stasiuk, S.; Schertzberg, M.; Angus McQuibban, G.;

539 Caffrey, C. R.; Cutler, S. R.; Tyers, M.; Giaever, G.; Nislow, C.; Fraser, A. G.; MacRae, C.

540 A.; Gilleard, J.; Roy, P. J., Caenorhabditis elegans is a useful model for anthelmintic

541 discovery. Nat. Commun. 2015, 6, doi: 10.1038/ncomms 8485.

542 (37) Williams, A. R.; Ropiak, H. M.; Fryganas, C.; Desrues, O.; Mueller-Harvey, I.;

543 Thamsborg, S. M., Assessment of the anthelmintic activity of medicinal plant extracts and

544 purified condensed tannins against free-living and parasitic stages of Oesophagostomum

545 dentatum. Parasit. Vectors 2014, 7, 518.

546 (38) Paolini, V.; Fouraste, I.; Hoste, H., In vitro effects of three woody plant and sainfoin

547 extracts on 3rd-stage larvae and adult worms of three gastrointestinal nematodes.

548 Parasitology 2004, 129, 69-77.

549 (39) Yang, W. Z.; Ametaj, B. N.; Benchaar, C.; Beauchemin, K. A., Dose response to

550 cinnamaldehyde supplementation in growing beef heifers: ruminal and intestinal digestion. $J$.

551 Anim. Sci. 2010, 88, 680-688.

552 (40) Ropiak, H. M.; Lachmann, P.; Ramsay, A.; Green, R. J.; Mueller-Harvey, I.,

553 Identification of structural features of condensed tannins that affect protein aggregation. 2016

554 (submitted).

555 (41) Stiernagle, T. Maintenance of C. elegans (February 11, 2006), WormBook, ed. The C.

556 elegans Research Community, WormBook, doi/10.1895/wormbook.1.101.1,

557 http://www.wormbook.org

558 (42) Manolaraki, F.; Sotiraki, S.; Stefanakis, A.; Skampardonis, V.; Volanis, M.; Hoste, H.,

559 Anthelmintic activity of some Mediterranean browse plants against parasitic nematodes.

560 Parasitology 2010, 137, 685-696. 
561 (43) Peña-Espinoza, M.; Boas, U.; Williams, A. R.; Thamsborg, S. M.; Simonsen, H. T.;

562 Enemark, H. L., Sesquiterpene lactone containing extracts from two cultivars of forage

563 chicory (Cichorium intybus) show distinctive chemical profiles and in vitro activity against

564 Ostertagia ostertagi. Int. J. Parasitol. Drugs Drug Resist. 2015, 5, 191-200.

565 (44) Bliss, C. I., The toxicity of poisons applied jointly. Ann. Appl. Biol. 1939, 26, 585-615.

566 (45) Williams, A. R.; Douglas, A. D.; Miura, K.; Illingworth, J. J.; Choudhary, P.; Murungi,

567 L. M.; Furze, J. M.; Diouf, A.; Miotto, O.; Crosnier, C.; Wright, G. J.; Kwiatkowski, D. P.;

568 Fairhurst, R. M.; Long, C. A.; Draper, S. J., Enhancing blockade of Plasmodium falciparum

569 erythrocyte invasion: assessing combinations of antibodies against PfRH5 and other

570 merozoite antigens. PLoS Pathog. 2012, 8, e1002991.

571 (46) Molan, A. L.; Meagher, L. P.; Spencer, P. A.; Sivakumaran, S., Effect of flavan-3-ols on

572 in vitro egg hatching, larval development and viability of infective larvae of Trichostrongylus

573 colubriformis. Int. J. Parasitol. 2003, 33, 1691-1698.

574 (47) Mohamed, A. S. A.; Mori, T.; Islam, S. Q.; Sato, M.; Yamasaki, T., Lethal activity of

575 gallo- and condensed tannins against the free-living soil-inhabiting nematode, Caenorhabditis

576 elegans. J. Pest. Sci. 2000, 25, 410-415.

577 (48) Spiegler, V.; Sendker, J.; Petereit, F.; Liebau, E.; Hensel, A., Bioassay-guided

578 fractionation of a leaf extract from Combretum mucronatum with anthelmintic activity:

579 oligomeric procyanidins as the active principle. Molecules 2015, 20, 14810.

580 (49) Barrau, E.; Fabre, N.; Fouraste, I.; Hoste, H., Effect of bioactive compounds from

581 Sainfoin (Onobrychis viciifolia Scop.) on the in vitro larval migration of Haemonchus

582 contortus: role of tannins and flavonol glycosides. Parasitology 2005, 131, 531-538.

583 (50) Hsu, F. L.; Li, W. H.; Yu, C. W.; Hsieh, Y. C.; Yang, Y. F.; Liu, J. T.; Shih, J.; Chu, Y. J.;

584 Yen, P. L.; Chang, S. T.; Liao, V. H., In vivo antioxidant activities of essential oils and their 
constituents from leaves of the Taiwanese Cinnamomum osmophloeum. J. Agric. Food Chem.

586

587

588

589

590

591

592

593

594

595

596

597

598

599

600

601

602

603

604

605

606

607

608 2012, 60, 3092- 3097.

(51) Michiels, J.; Missotten, J.; Dierick, N.; Fremaut, D.; Maene, P.; De Smet, S., In vitro degradation and in vivo passage kinetics of carvacrol, thymol, eugenol and transcinnamaldehyde along the gastrointestinal tract of piglets. J. Sci. Food Agric. 2008, 88, 23712381 .

(52) Desrues, O.; Peña-Espinoza, M.; Hansen, T. V.; Mueller-Harvey, I.; Enemark, H. L.; Thamsborg, S. M., Anthelmintic effects of sainfoin against different cattle nematodes may be linked to concentration of condensed tannins in different gut compartments. In: 25 th International Conference of the World Association for the Advancement of Veterinary Parasitology 2015; Liverpool, UK.

(53) Links, M. R.; Taylor, J.; Kruger, M. C.; Taylor, J. R. N., Sorghum condensed tannins encapsulated in kafirin microparticles as a nutraceutical for inhibition of amylases during digestion to attenuate hyperglycaemia. J. Funct. Foods 2015, 12, 55-63.

(54) Martínez-Ortíz-de-Montellano, C.; Arroyo-López, C.; Fourquaux, I.; Torres-Acosta, J. F. J.; Sandoval-Castro, C. A.; Hoste, H., Scanning electron microscopy of Haemonchus contortus exposed to tannin-rich plants under in vivo and in vitro conditions. Exp. Parasitol. 2013, 133, 281-286.

(55) Malisch, C. S.; Lüscher, A.; Baert, N.; Engström, M. T.; Studer, B.; Fryganas, C.; Suter, D.; Mueller-Harvey, I.; Salminen, J.-P., Large variability of proanthocyanidin content and composition in sainfoin (Onobrychis viciifolia). J. Agric. Food Chem. 2015, 63, 1023410242.

(56) Brunet, S.; Hoste, H., Monomers of condensed tannins affect the larval exsheathment of parasitic nematodes of ruminants. J. Agric. Food Chem. 2006, 54, 7481-7487. 
609 (57) Page AP, Johnstone IL: The cuticle (March 19, 2007), WormBook, ed. The C. elegans

610 Research Community, WormBook, doi/10.1895/wormbook.1.138.1,

611 http://www.wormbook.org.

612 (58) Fetterer, R. H.; Rhoads, M. L., Biochemistry of the nematode cuticle: relevance to

613 parasitic nematodes of livestock. Vet. Parasitol. 1993, 46, 103-111.

614 (59) Wright, K. A.; Thomson, J. N., The buccal capsule of Caenorhabditis elegans

615 (Nematoda: Rhabditoidea): an ultrastructural study. Can. J. Zool. 1981, 59, 1952-1961.

616 (60) Lints, R., Hall, D. H. 2009. The cuticle. In WormAtlas. doi:10.3908/wormatlas.1.12.

617 (61) Bisoffi, M.; Marti, S.; Betschart, B., Repetitive peptide motifs in the cuticlin of Ascaris 618 suum. Mol. Biochem. Parasitol. 1996, 80, 55-64.

619 (62) Mika, A.; Gołębiowski, M.; Szafranek, J.; Rokicki, J.; Stepnowski, P., Identification of 620 lipids in the cuticle of the parasitic nematode Anisakis simplex and the somatic tissues of the 621 Atlantic cod Gadus morhua. Exp. Parasitol. 2010, 124, 334-340.

622 (63) Yu, X.; Chu, S.; Hagerman, A. E.; Lorigan, G. A., Probing the interaction of polyphenols 623 with lipid bilayers by solid-state NMR spectroscopy. J. Agric. Food Chem. 2011, 59, 67836246789.

625 (64) Verstraeten, S. V.; Jaggers, G. K.; Fraga, C. G.; Oteiza, P. I., Procyanidins can interact 626 with Caco-2 cell membrane lipid rafts: Involvement of cholesterol. Biochim. Biophys. Acta 627 Biomembranes 2013, 1828, 2646-2653.

628 (65) Mueller-Harvey, I., Unravelling the conundrum of tannins in animal nutrition and health. 629 J. Sci. Food Agric. 2006, 86, 2010-2037.

630 (66) Jackson, F.; Hoste, H., In vitro methods for the primary screening of plant products for 631 direct activity against ruminant gastrointestinal nematodes. In: In vitro screening of plant 632 resources for extra-nutritional attributes in ruminants: nuclear and related methodologies, 633 Vercoe, P. E.; Makkar, H. P. S.; Schlink, A. C., Eds. Springer Netherlands: 2010; pp 25-45. 
634 (67) National Centre for the Replacement Refinement \& Reduction of Animals in Research.

635 NC3Rs. (https://www.nc3rs.org.uk/the-3rs) (Accessed on 04/09/15)

636

637 Acknowledgment for funding sources

638 This study was supported by an EU Marie Curie Initial Training Network

639 (PITN-GA-2011-289377, "LegumePlus") and the Danish Council for Independent

640 Research (Technology and Production Sciences, Grant \# 12-126630).

$641 \quad$ Notes

642 The authors declare no competing financial interest. 


\section{$643 \quad$ Figure captions}

644 Figure 1. Example of B-type condensed tannin. Substitution of $\mathrm{R}_{4}$ or $\mathrm{R}_{5}$ by galloyl group 645 results in galloylation of condensed tannin.

646

647 Figure 2. Effects of condensed tannins (CT) rich or moderately rich in prodelphinidins on 648 adult $C$. elegans motility; (A) white clover flower F2 (n=2), (B) redcurrant leaf F2 (n=2),

649 blackcurrant leaf (no. 1) F2 (n=3), (D) blackcurrant leaf (no. 2) F2 and F3 (n=1, for each

650 sample), (E) birch leaf F2 (n=3), (F) sainfoin aerial part F2 (n=2), (G) yellow iris leaf F2

$651(\mathrm{n}=1)$; where, $\mathrm{n}$ is the number of independent experiments shown with different

652 markers/lines; the error bars show the standard deviation from triplicate measurements at 653 each CT treatment of one independent experiment; data have been corrected to CT content 654 (CT g/100 g of fraction).

655

656 Figure 3. Effects of procyanidin-rich condensed tannins (CT) on adult C. elegans motility;

657 (A) results of three independent experiments $(\mathrm{n}=3)$ with cocoa bean F2, (B) Tilia flower F2 $658(\mathrm{n}=3),(\mathrm{C})$ great water dock root F2 (n=3), (D) cocoa bean F2 and Tilia flower F2 (n=1, for 659 each sample at double the concentration of that used in A and B); where, $\mathrm{n}$ is the number of

660 independent experiments shown with different markers/lines; the error bars show the standard

661 deviation from triplicate measurements at each CT treatment of one independent experiment;

662 data have been corrected to CT content (CT g/100 $\mathrm{g}$ of fraction).

663

664 
665 Figure 4. Motility of adult C. elegans after exposure to condensed tannin (CT) fractions (1.5

666

667

668

669

670

671

672

673

674

675

676

677

678

679

680

681

682

683

684

685

686

687

688

689

690

$\mathrm{mg} / \mathrm{mL}$ ) with or without polyvinylpolypyrrolidone (PVPP) pre-treatment; negative control $100 \%$ motile; data from one independent experiment (number of wells: $n=6$ for negative control, $\mathrm{n}=6$ for PVPP control, $\mathrm{n}=3$ for PVPP/CT fraction or CT fraction).

Figure 5. Synergistic effects of condensed tannins (CT) and cinnamaldehyde (CIN) added at effective concentrations (EC) on C. elegans motility: (A) great water dock root F2 and CIN at $\mathrm{EC}_{25}$; (B) great water dock root F2 and CIN at $\mathrm{EC}_{50}$; and (C) Tilia flower F2 and CIN at $\mathrm{EC}_{25}$. One independent experiment, where the error bars show the standard deviation from triplicate measurements at each CT treatment; data are corrected to CT content (CT g/100 g of fraction). Asterisks indicate that the predicted additive and observed values differed significantly $(* * * \mathrm{P}<0.001 ; * * \mathrm{P}<0.01 ; * \mathrm{P}<0.05$ by two-way ANOVA with Bonferroni posthoc testing). Repetition of experiment (A) and (C) gave a similar pattern (data not shown).

Figure 6. Scanning electron microscopy of cuticle surface (left column: A, C, E, G) and sensilla of the lip region (right column: B, D, F, H) of adult C. elegans, after treatment with condensed tannin (CT) fraction $(1.5 \mathrm{mg} / \mathrm{mL})$; (A, B) control (buffer), (C, D) Tilia flower F2 (1.38 CT mg/mL), (E, F) birch leaf F2 (0.95 CT mg/mL), (G, H) blackcurrant leaf F2 (1.16 CT mg/mL); scale bars $5 \mu \mathrm{m}$; magnification: 3500x for D, E, G; 5000x for A-C, F, H.

Figure 7. Scanning electron microscopy of cuticle surface (left column: A, C, E, G, I, K) and sensilla of the lip region (right column: B, D, F, H, J) of young adult and adult C.elegans, after treatment with condensed tannin (CT) fractions $(1.5 \mathrm{mg} / \mathrm{mL})$ or/and cinnamaldehyde (at $\mathrm{EC}_{25}$ or $2 \mathrm{mM}$ ), where (A, B): control (buffer), (C, D): great water dock root F2 (0.95 CT $\mathrm{mg} / \mathrm{mL}),(\mathrm{E}, \mathrm{F})$ : cinnamaldehyde at $\mathrm{EC}_{25},(\mathrm{G}, \mathrm{H})$ : cinnamaldehyde at $2 \mathrm{mM}$, (I-K): great water dock root $\mathrm{F} 2(0.95 \mathrm{CT} \mathrm{mg} / \mathrm{mL})$ and cinnamaldehyde at $\mathrm{EC}_{25}(0.605 \mathrm{mM})$; scale bars 5 
$691 \mu \mathrm{m}$ (or $2 \mu \mathrm{m}$ for $\mathrm{D}-\mathrm{H} ; 10 \mu \mathrm{m}$ for $\mathrm{K}$ ); magnification: 3500x for $(\mathrm{K})$; $5000 \mathrm{x}$ for $(\mathrm{A}-\mathrm{C}, \mathrm{I}) ; 6500 \mathrm{x}$ 692 for (D-G, J); and 8000x for (H). 
Table 1. Condensed tannin (CT) content; mean degree of polymerization (mDP); molar percentages of: procyanidin, cis-flavan-3-ols and

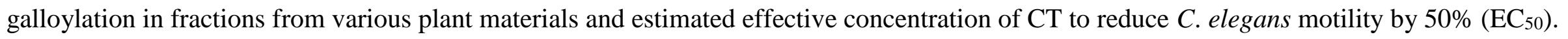

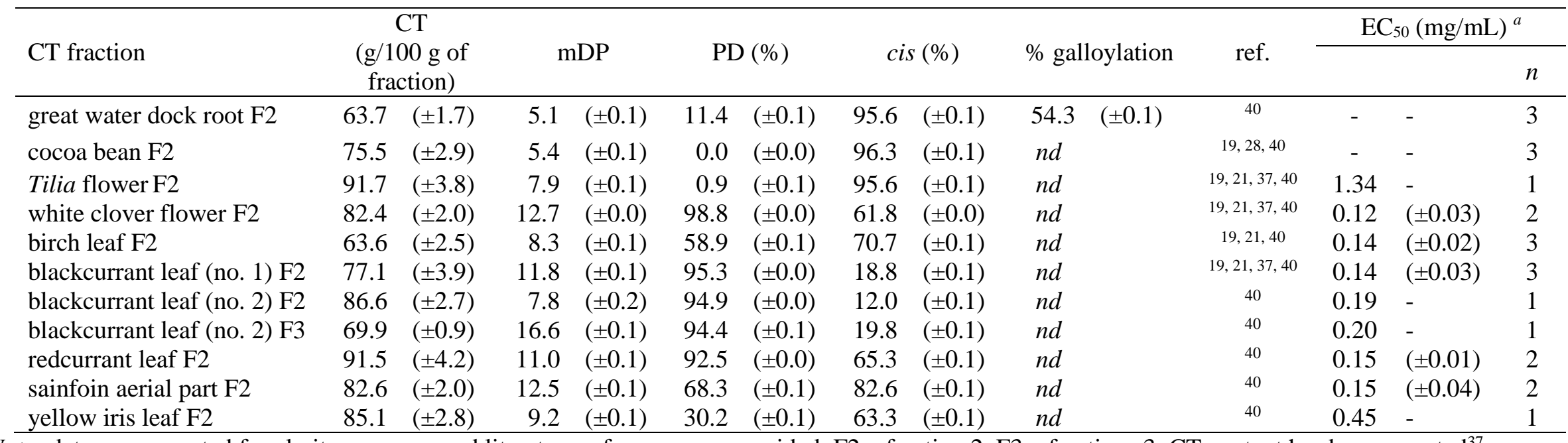

Note: data are presented for clarity purposes and literature references are provided, F2 - fraction 2, F3 - fractions 3; CT content has been reported ${ }^{37}$

(calculated with mass response factor calculations); $\left({ }^{a}\right)$ data have been corrected for CT content (CT g/100 g of fraction); $(n)$ number of independent experiments (composed of triplicate measurements at each CT concentration treatment); (nd) not detected; (-) not determined. Standard deviation in parentheses. 

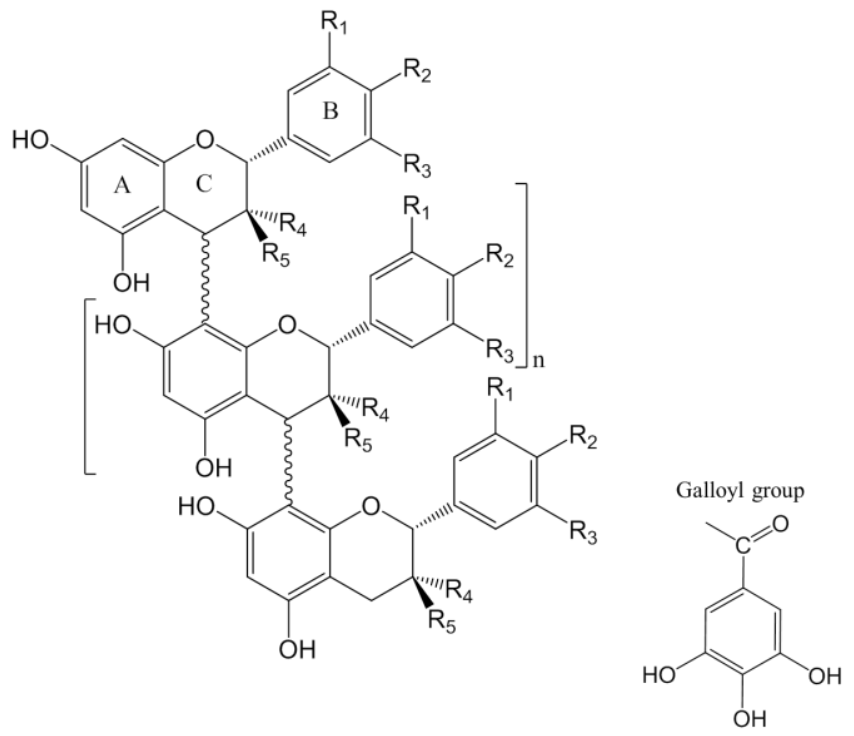

\begin{tabular}{llcccccr}
\hline Condensed tannin & Flavan-3-ol subunit & Stereochemistry & $\mathrm{R}_{1}$ & $\mathrm{R}_{2}$ & $\mathrm{R}_{3}$ & $\mathrm{R}_{4}$ & $\mathrm{R}_{5}$ \\
\hline \multirow{2}{*}{ procyanidin } & catechin & trans & $\mathrm{OH}$ & $\mathrm{OH}$ & $\mathrm{H}$ & $\mathrm{H}$ & $\mathrm{OH}$ \\
\cline { 3 - 5 } & epicatechin & cis & $\mathrm{OH}$ & $\mathrm{OH}$ & $\mathrm{H}$ & $\mathrm{OH}$ & $\mathrm{H}$ \\
\multirow{2}{*}{ prodelphinidin } & gallocatechin & trans & $\mathrm{OH}$ & $\mathrm{OH}$ & $\mathrm{OH}$ & $\mathrm{H}$ & $\mathrm{OH}$ \\
& epigallocatechin & cis & $\mathrm{OH}$ & $\mathrm{OH}$ & $\mathrm{OH}$ & $\mathrm{OH}$ & $\mathrm{H}$ \\
\hline
\end{tabular}

Figure 1. 

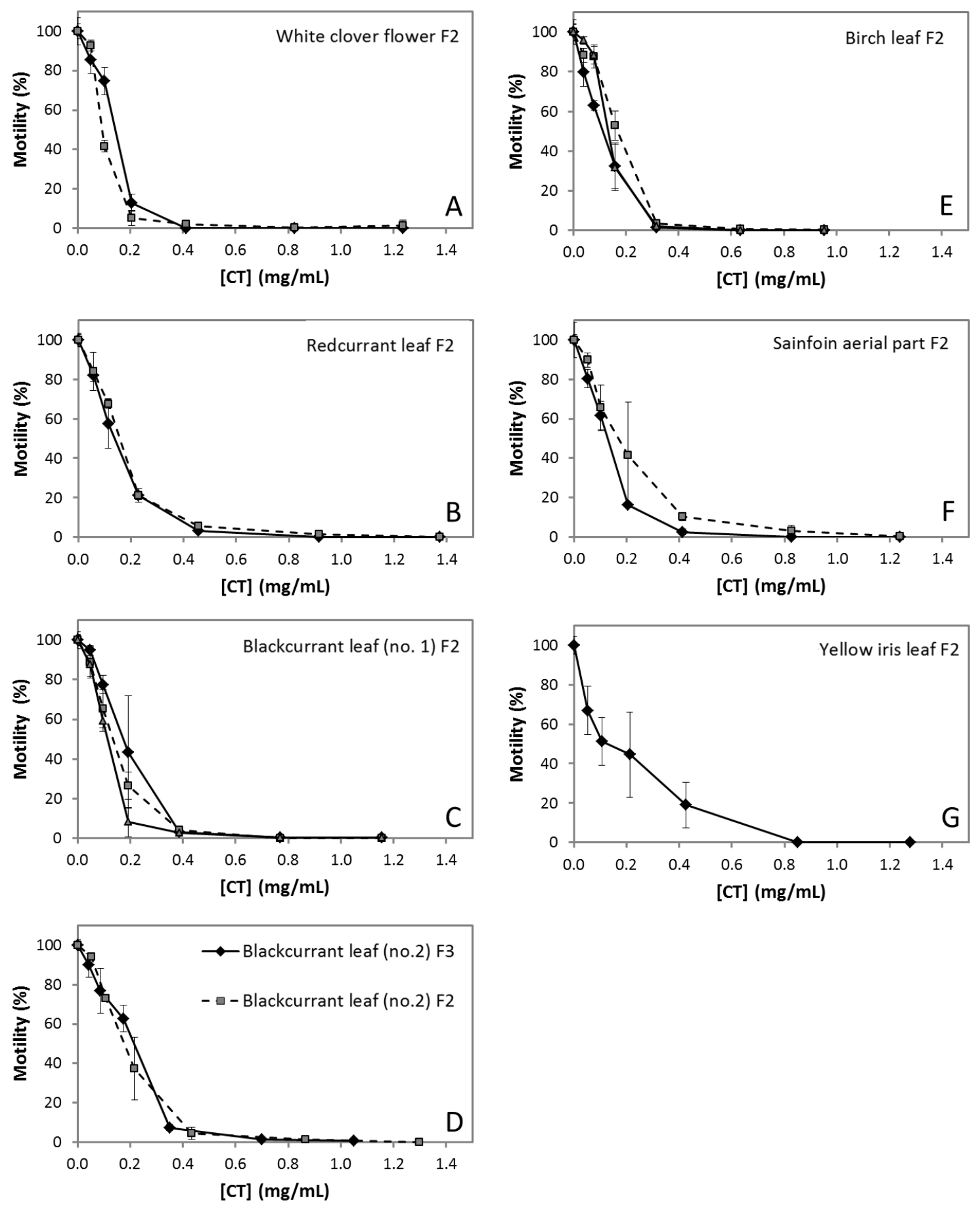

\section{Figure 2.}



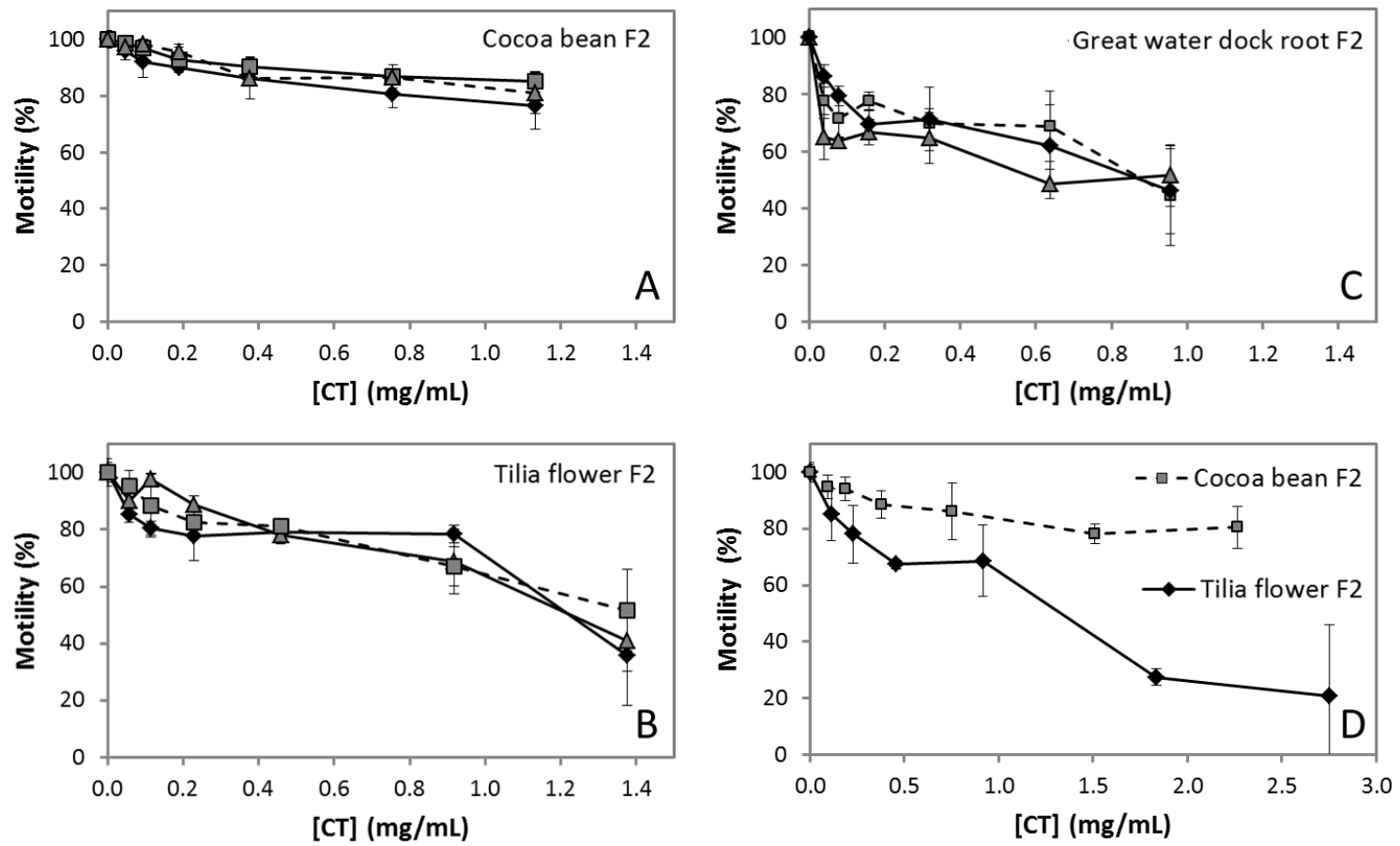

Figure 3. 


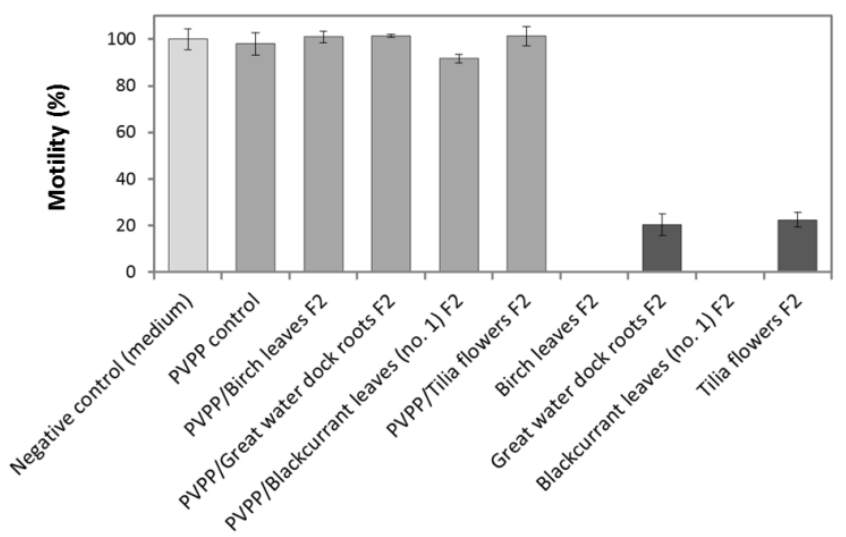

Figure 4. 

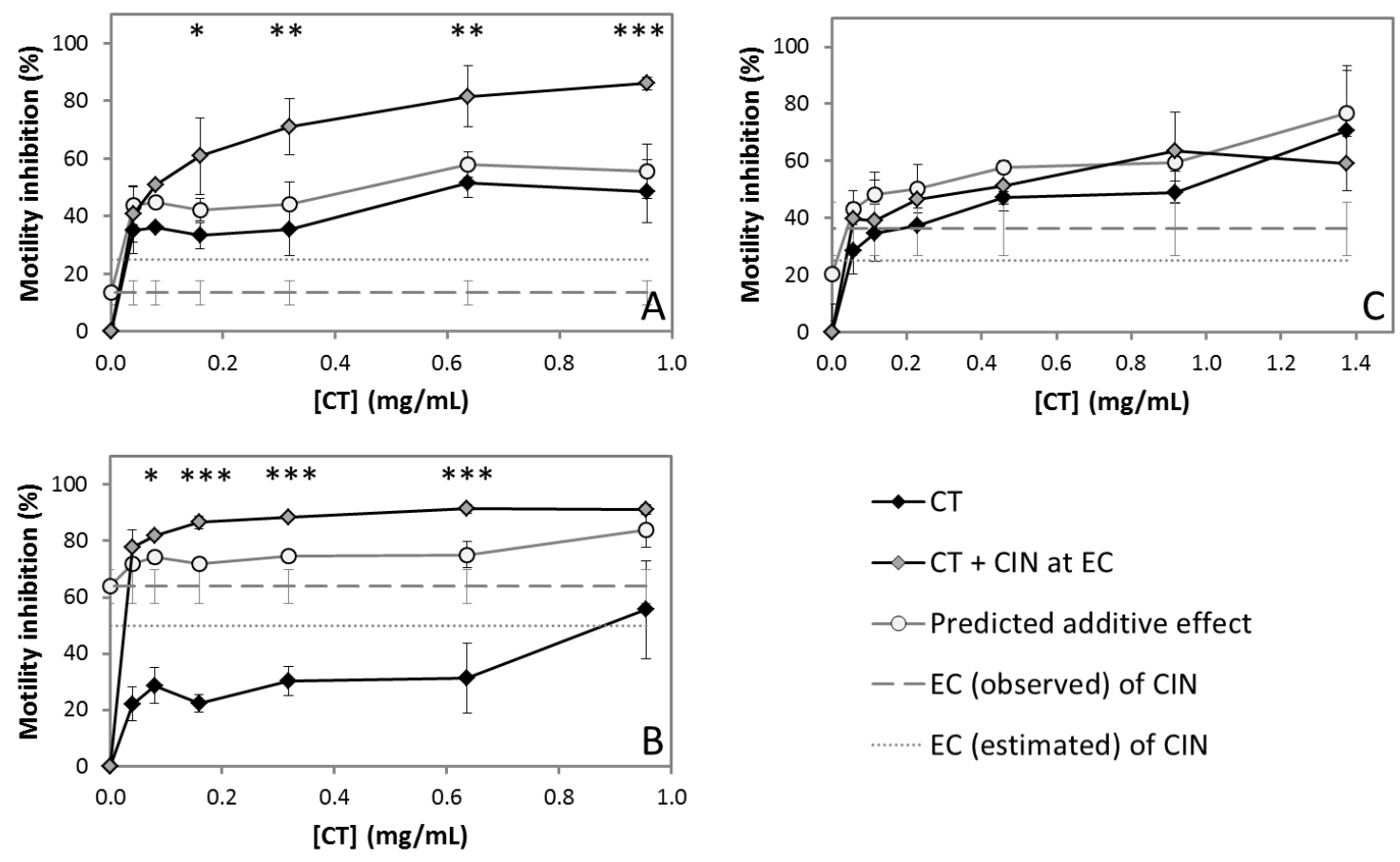

$\rightarrow$ CT

$\checkmark-\mathrm{CT}+\mathrm{CIN}$ at EC

$\multimap-$ Predicted additive effect

- - EC (observed) of CIN

........ EC (estimated) of CIN

Figure 5. 


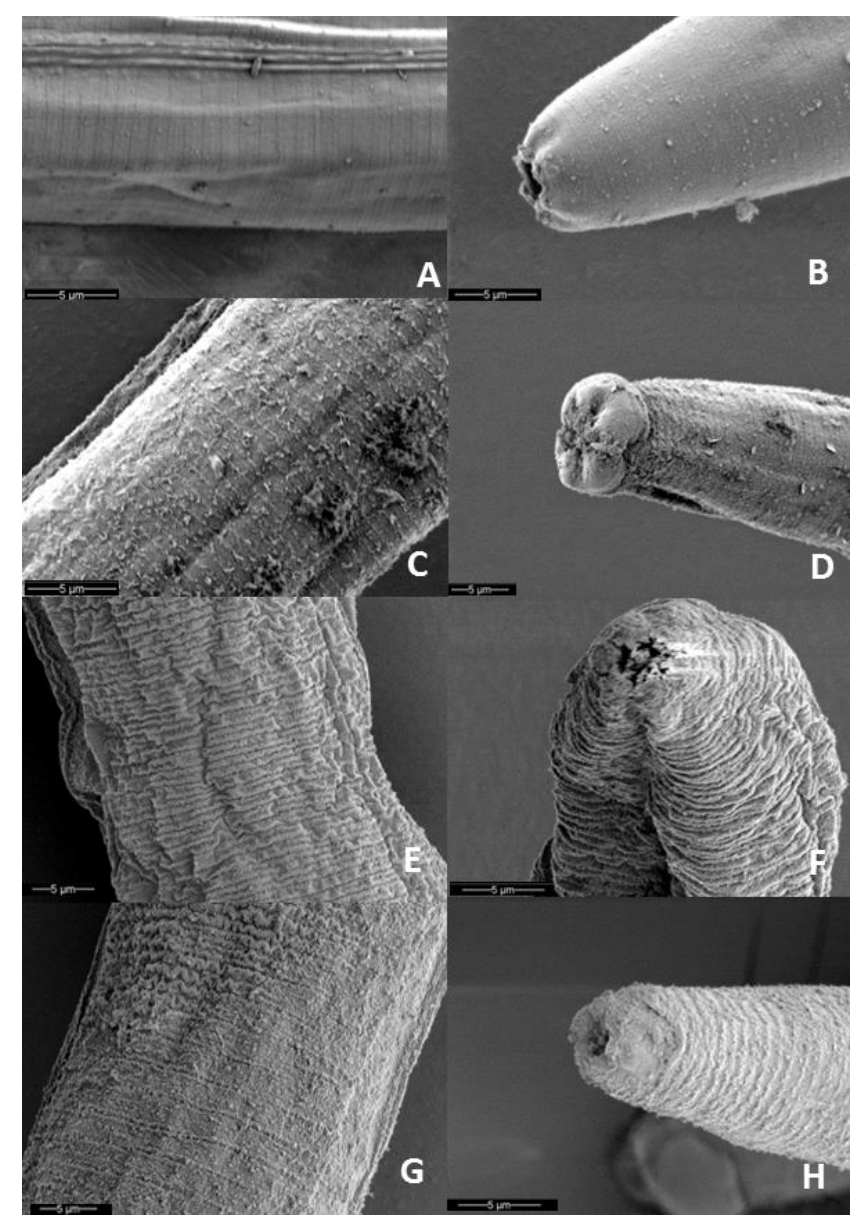

Figure 6. 


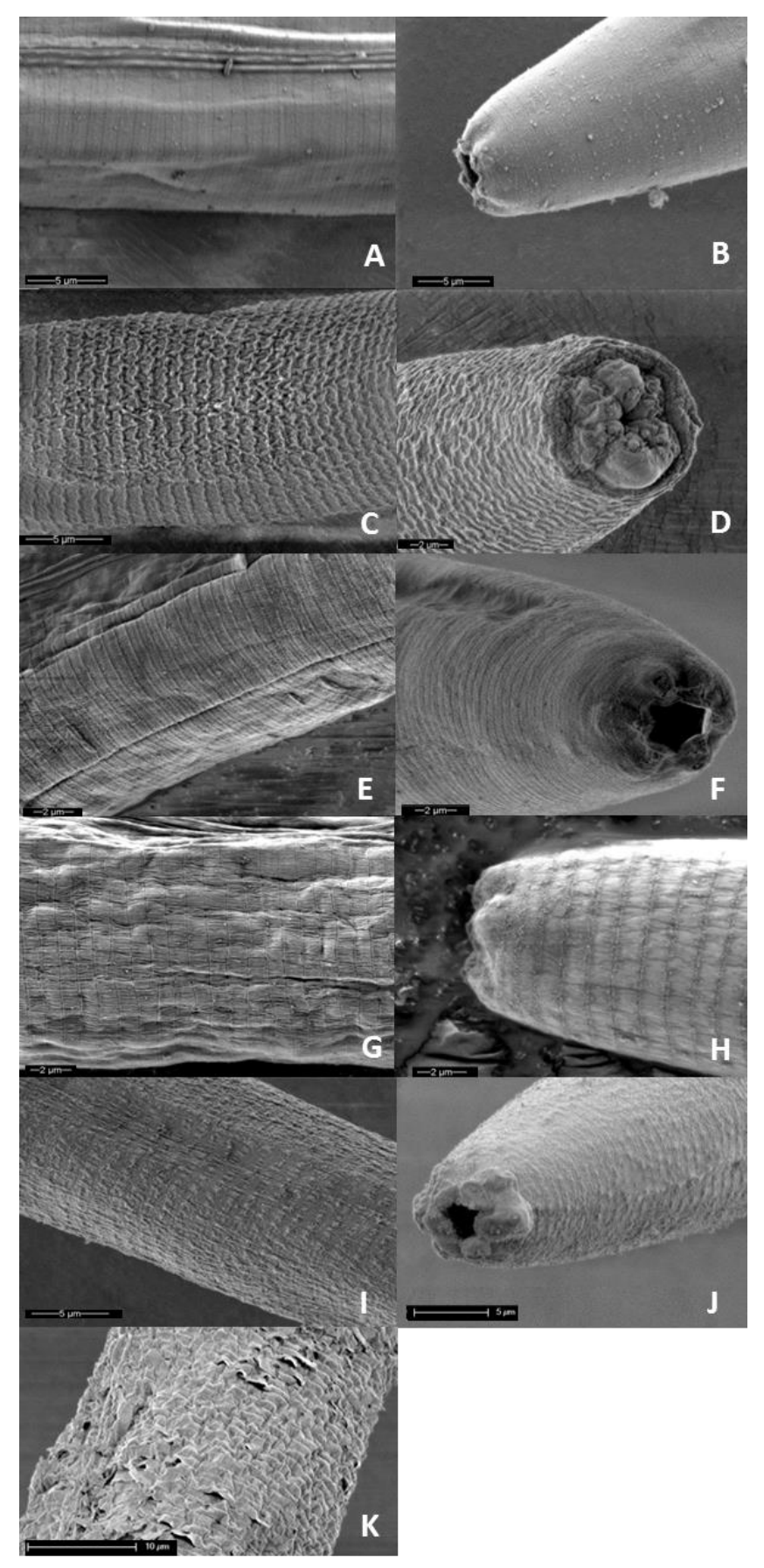

Figure 7. 


\section{TABLE OF CONTENTS GRAPHICS}

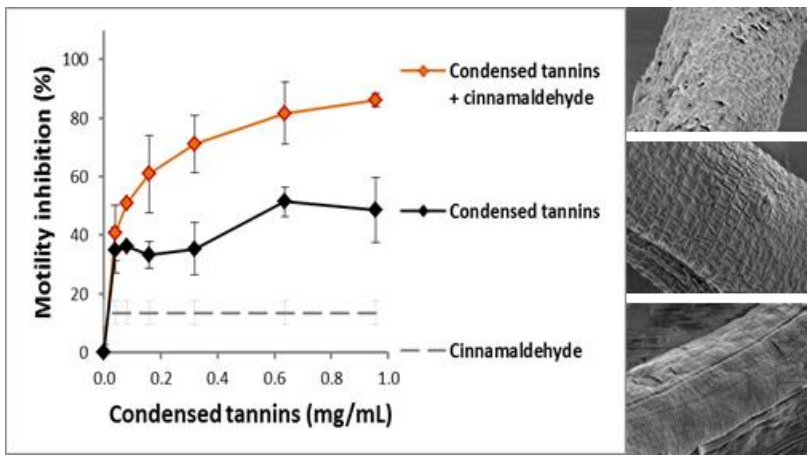

